\title{
Coupled Zircon-Rutile U-Pb \\ Chronology: LA ICP-MS dating and geological significance
}

\author{
LAURA BRACCIALI ${ }^{1,2}$ \\ ${ }^{1}$ Thermo Fisher Scientific, Bremen, Germany, \\ laura.bracciali@thermofisher.com \\ ${ }^{2}$ Geochronology and Tracers Facility, British Geological \\ Survey, Nottingham, UK
}

Significant technological development of mass spectrometers and laser ablation systems in the last decades have made U-Pb dating by Laser Ablation ICP-MS one of the most popular and successful isotopic techniques available to the Earth Sciences. The method allows fast sampling, high spatial resolution and good precision (with absolute $\mathrm{U} / \mathrm{Pb}$ age resolution for zircon of ca. $2 \%, 2 \mathrm{~s}$ ).

A continuously improved understanding of the behaviour of the U-Pb isotopic system in different U-bearing mineral chronometers, in particular the mechanisms controlling retention versus diffusion of radiogenic $\mathrm{Pb}$ in response to geological processes, have opened new fields of application. Thermally-controlled $\mathrm{Pb}$ volume diffusion in rutile is effective at mid- to low-crustal temperatures $\left(>450{ }^{\circ} \mathrm{C}\right)$ hence the $\mathrm{U}-\mathrm{Pb}$ rutile thermochronometer is ideally suited to constrain crustal cooling and exhumation (with a precision only slightly worse than zircon). In contrast, zircon growth generally occurs at higher temperatures where $\mathrm{Pb}$ diffusion rates in this mineral are negligibly slow at geological scales. The zircon $\mathrm{U}-\mathrm{Pb}$ chronometer is thus an ideal time-tracker of igneous and metamorphic crystallization.

A growing body of research focuses on the combined application of LA ICP-MS U-Pb bedrock and detrital chronology of rutile and zircon from the same rock. In sediment provenance studies such an approach, particularly when complemented by lower- $T$ thermochronometry data, allows a comprehensive isotopic characterization of the sources. Published examples from different geological settings will be reviewed, with an emphasis on the benefits of applying detrital zircon-rutile U-Pb chronology as a coupled provenance proxy [1, and references therein].

[1] Bracciali (2019), Geosciences 9, 467. 